\title{
Opera History, the Travel Edition
}

\author{
Jonathan Hicks \\ University of Aberdeen, Scotland \\ Email: jonathan.hicks@abdn.ac.uk.
}

Jens Hesselager, ed., Grand Opera Outside Paris: Opera on the Move in Nineteenth-Century Europe. Abingdon: Routledge, 2018. 250pp.

This book has been in my bag for a long time and, on reflection, I am glad that I have read it gradually. When the central premise is so simple - Grand Opera Outside Paris is, indeed, about Grand Opera outside Paris - the payback comes in the detail of individual chapters and the slow emergence of a Europe-wide survey of encounter and exchange. The volume's editor, Jens Hesselager, provides an erudite and generous introduction, beginning with the familiar difficulty of defining grand opera and the importance of attending to specific performance contexts. In the first instances, of course, this meant the Paris Opéra, and Hesselager draws our attention to Sarah Hibberd's observation that the coherence of the genre was initially established 'more through the licensing requirements of [this] institution than by [any] specific dramatic content' (1). ${ }^{1}$ From here, the introduction gently encourages us to look outward.

Grand opera has, after all, not only been understood in relation to the Opéra but more broadly, following Anselm Gerhard's influential analysis, in relation to the urban modernity of nineteenth-century Paris. ${ }^{2}$ But there are still larger horizons in view here, as Hesselager then quotes from Jürgen Osterhammel's The Transformation of the World to expand the scope of discussion considerably further: 'Around 1830, Parisian musical history was global musical history' (2). ${ }^{3}$ We learn that Osterhammel's bon mot was borrowed from Michael Walter, who contrasted Parisian globality with Milanese locality (2). ${ }^{4}$ Crucially, Hesselager does not dispute the 'global superpower' status of the Opéra, c.1830. However, he urges that 'this should not be taken to mean that global, or even European, opera history could for this reason be written exclusively as the history of its cultural centre(s)' (2). Without seeking to underplay the historical 'centralisation of resources', Hesselager advocates for 'a concomitant development of a decentralised historiography, where peripheries are not mistaken for areas of peripheral interest, as stuff for "local music history" only' (3). He follows this plea with a deceptively simple

\footnotetext{
${ }^{1}$ Sarah Hibberd, French Grand Opera and the Historical Imagination (Cambridge, 2009), 2.

${ }^{2}$ See Anselm Gerhard, The Urbanization of Opera: Music Theater in Paris in the Nineteenth Century, trans. Mary Whittall (Chicago, 1998).

${ }^{3}$ Jürgen Osterhammel, The Transformation of the World: A Global History of the Nineteenth Century, trans. Patrick Camiller (Princeton, 2014), 5.

${ }^{4}$ Michael Walter, 'Die Oper ist ein Irrenhaus': Sozialgeschichte der Oper im 19. Jahrhundert (Stuttgart, 1997$), 37$. 
question: 'So "where" did opera happen in the nineteenth century?' Far from taking the place of grand opera for granted, then, this is a volume that seeks to articulate the complexity of its generic geography. There is nothing wrong, Hesselager suggests, with a focus on 'origins' and the 'sites and circumstances of first performances', but we might equally ask 'How operas travelled and where they ended up being performed for various reasons, how they were performed, by whom, how critics and audiences reacted, how such works were mediated, transformed and given new meanings by technologies of distribution, translation, adaptation, censorship, etc.' (3).

Readers of this journal may feel they have been here before. Laura Protano-Biggs's special issue on 'Nineteenth-Century Grand Opéra on the Move' appeared in print a year before Grand Opera Outside Paris. ${ }^{5}$ Her introduction began by noting how 'few genres have seemed so fastened to one institution as grand opéra', not least because 'our discipline has long been obsessed with the origins of things'. ${ }^{6}$ In response, the special issue aimed to 'cast aside focus on the Opéra, in order to revisit the ways in which grands opéras were geographically mobile'. One of the contributors to that special issue (Sarah Hibberd) also wrote a chapter for the volume under review and, unsurprisingly, there is further overlap in terms of the sites (e.g., London) and works (e.g., Gustave III) discussed in both collections of essays. What is more, two years earlier, in 2015, the first Transnational Opera Studies Conference (tosc@Bologna) had already helped to institutionalise a turn away from methodological nationalism, with a keynote, subtitled 'Questioning national categories of analysis', in which Axel Körner argued for a greater dialogue between transnational history and opera studies. ${ }^{8}$ Given that Körner was among the contributors to Protano-Biggs's special issue, and two of the contributors to Hesselager's volume also presented at tosc@Bologna, it is clear there has been a gathering of interest in such topics. The 2014 conference in Copenhagen that led to the book under review can be viewed as part of this broader movement, since it took place in the context of a research project on 'Transnational Practices and Touring Artists in the Long 19th-Century Norden'. This conference included scholars who would go on to contribute to similar initiatives, notably Richard Langham Smith and Clair Rowden, whose Carmen Abroad project resulted in a volume about Bizet's Opera on the Global Stage. ${ }^{10}$

You might therefore say that Hesselager's book is one that goes with the flow: unmooring grand opera from Paris, such as tracking Carmen abroad, is an exercise in the increasingly common practice of transnational opera history. In attempting to redraw the map of expressive culture so that the border lines between nations appear no more prominent than the railway lines between cities or the shipping routes between ports - or, for

\footnotetext{
${ }^{5}$ Laura Protano-Biggs, ed., 'Introduction', Cambridge Opera Journal (special issue: Nineteenth-Century Grand Opéra on the Move), 29/1 (2017).

${ }^{6}$ Protano-Biggs, 'Introduction', 1.

${ }^{7}$ Protano-Biggs, 'Introduction', 2.

${ }^{8}$ The full title of Körner's keynote was 'From Transnational History to Transnational Opera: Questioning National Categories of Analysis'. An article based on this address is available in Italian: Axel Körner, 'Dalla storia transnazionale all'opera transnazionale: per una critica delle categorie nazionali', trans. Valeria Lucentini and Livio Marcaletti, Il Saggiatore Musicale 24/1 (2017), 81-98. The 2015 conference programme is included in the online Archivo Del Canto, hosted by the Università di Bologna: https://archiviodelcanto.dar.unibo.it/tosc/. There have been two further conferences in this series (tosc@Bern in 2017 and tosc@Paris in 2019) with the next instalment (tosc@Bayreuth) scheduled for 2022.

${ }^{9}$ The details and funders of the 2014 conference are given in Hesselager's acknowledgements. The 'Norden' focus is reflected in contributors, with two each from institutions in Sweden, Finland, and Germany and one apiece from Denmark, England, and Switzerland (the outliers are Portugal and Italy). Conspicuous by their absence are contributors based in France.

${ }^{10}$ See carmenabroad.org as well as Richard Langham Smith and Clair Rowden, eds., Carmen Abroad: Bizet's Opera on the Global Stage (Cambridge, 2020).
} 
that matter, the notional dotted lines between various nodes in actors' journeys around the global networks of musical and theatrical practice - the contributors to this volume are likely to meet little academic opposition. Indeed, it is striking how, in Emanuele Senici's recent book about Rossini's operas, a departure from the new orthodoxy requires justification: 'My investigation ... purposefully avoids a transnational perspective', Senici writes. 'Such a perspective would be most apt for these internationally successful works, but I am convinced it needs to be preceded by a specifically Italian one. ${ }^{11}$ Even at the point of strategically recentring the nation (or at least the Italian peninsula), Senici is at pains to acknowledge the values of a more-than-Italian frame of reference: 'No greater compliment could be paid to this study', he writes, 'than if it contributed to a properly transnational inquiry into the profound reasons for the enormous success of Rossini's Italian operas within and without Europe. ${ }^{, 12}$

In light of Senici's remarks, it seems that transnationalism is well on the way to becoming a default mode of opera history, and that is reason enough to pause and take stock. While Grand Opera Outside Paris is only one example of a broader trend, a detailed examination of this volume provides an opportunity to ask how transnationalism works in practice. My aim here is not to evaluate the arguments for transnational enquiry, in part because it strikes me that the case has already been made and won. As evidenced by Hesselager's compelling yet uncontroversial introduction, it is hard to imagine anyone being upset by the principle of the transnational turn. The more pressing questions, I think, are the practical ones. How do we write about works without borders? What, besides the obvious, distinguishes a destination-oriented study from one fixated on origins? And, if the objective is to understand operatic culture on the move, where do we begin?

\section{Spot the difference}

I suggest we turn to Laura Moeckli's chapter, which immediately follows Hesselager's introduction and opens with the apparent incongruity of 'monumental Parisian masterworks' on medium-sized provincial stages. The specific stage in question is that of Basel's Theater auf dem Blömlein, 'a venue which certainly did not have the material, personnel or experience usually deemed necessary for lavish grand opera productions' (13). Moeckli tells us that the 'minimalist performances' found in Basel were, in fact, typical of theatrical practice across Europe 'and even beyond' in the nineteenth century. You can see why her chapter was chosen to go first: its theoretical framework exemplifies that of the volume as a whole; its studied revisionism sets the tone for much of what follows. My only complaint is that Moeckli could have been bolder. While reminding us of grand opera's demonstrable reach, the author is quick to circumscribe the value of extra-Parisian performances: 'What is interesting', Moeckli writes, 'is obviously not the aesthetic quality or authorial "authenticity" of these marginal operatic events, which must, in most cases, have been quite unsatisfactory; rather', she continues, 'it is the fact that each performance, however peripheral, contributed to the phenomenon of historical grand opera, shaping the scope, impact and meaning of these epochal artworks in time and space' (13). I have no quarrel with the suggestion that operas built for large metropolitan houses took on new shapes and meanings in smaller venues, but I do query the assumption that opera scholars obviously care little for the aesthetic qualities of performances away from the capitals of European culture. Likewise, I do not see why the study of specific

\footnotetext{
${ }^{11}$ Emanuele Senici, Music in the Present Tense: Rossini's Operas in Their Time (Chicago, 2019), 3.

12 Senici, Music in the Present Tense, 3.
} 
'peripheral' practices can only be justified in almost deferential terms, as contributing a little bit of new material to the bigger patchwork of 'the phenomenon of historical grand opera'.

However, I should be careful not to give the wrong impression. Moeckli's chapter, like the volume as a whole, exhibits considerable care in its treatment of 'marginal operatic events'. The sheer amount of attention the authors have lavished on archives and institutions off the beaten track (at least as far as conventional grand opera history is concerned) is remarkable. While I cannot address every chapter in this review, it is worth noting that, in addition to London and Basel, contributors to this volume discuss grand opera in Weimar, Copenhagen, Stockholm and Helsinki. There is also a trio of chapters on cultural and theatrical 'responses' to grand opera (i.e., works influenced by the Parisian repertory rather than performances of that repertory) in Portugal, Russia and Spain. Not only does the volume exhibit a widely dispersed set of case studies (albeit one with a northern European emphasis), but it also displays an interest in multi-local and non-radial geographies that confound simple relations between centre and periphery. Moeckli, for instance, refers to the historical importance of 'threshold cities' (14) and describes Switzerland as a country 'situated at a crossroads of several linguistic and cultural regions of Europe, [which] offers fertile grounds for studying transnational perceptions and reception of grand opera beyond Paris' (13). Still, I wonder whether some contributors could have done more to banish the spectre of cultural cringe and the nagging sense of apology for discussing the history of lesser-known stages - the 'destinations' of Hesselager's introduction. Part of the problem, I suspect, is that marginality has aesthetic as well as geographic connotations. Like the damning epithet provincial, it can suggest a world of tempered ambitions and pale imitations. As we find throughout the volume, this was something of which nineteenth-century commentators, within and without Switzerland, were acutely aware.

Take the (probable) Swiss premiere of La muette de Portici in 1831. 'It was no small task', we read in a passage from the Journal de Genève, 'to present this work in Geneva. Deprived of the ballets, the decor, the theatrical pomp that one finds only at the Paris Opéra, the performance could only present here a very imperfect copy, a sort of caricature of a painting refined in all its parts' (15). Similarly, in Basel in the 1830s and 1840s, the Theater auf dem Blömlein relied on local amateurs to supplement the professional members of chorus and orchestra. According to one of Moeckli's sources, the results were less than impressive. Reporting on the local premiere of Die Jüdin in 1845, the critic for the Allgemeines Intelligentzblatt der Stadt Basel questioned the ability of the chorus to sing in tune: 'This is not surprising when one only has two dozen throats at one's disposal, and this chorus, besides being crowd, judge, assessor, knight and cleric, must also function as a ballet that has barely danced itself out of breath before having to sing again' (22). Owe Ander's essay on La juive in 1860s Stockholm provides another case of perceived inadequacy. Here, one early reviewer acknowledged the 'magnificent scenery' at the city's Royal Theatre before adding the killer caveat: 'as great as can be expected and realised here' (87). As with the criticism in Basel, we can detect a performance of privileged knowledge. Ander observes that the Stockholm reviewer 'was evidently eager to give the impression of having witnessed the opera on other operatic stages' (87). Such an attitude - beholden to bigger cities, bedazzled by grander spectacles - is an inescapable feature of the historical sources under discussion, and one that I think bears further scrutiny in the context of a wider consideration of transnational opera studies.

It seems clear that, for many nineteenth-century critics, the Opéra represented a gold standard against which other venues and ventures were necessarily judged. As we find in this volume, such judgements could be harsh or fair, cruel or kind, yet they almost always came with an air of condescension. The curious thing, evident in the examples discussed 
by both Moeckli and Ander, is that local critics conspired in condescending to their friends and neighbours. Assuming for the sake of argument that most Parisian commentators lost little sleep over the business of Swiss or Swedish theatres, it seems the inferiority complex was primarily a phenomenon of recipient communities, that is, those institutions, audiences and commentators who relied on imported operatic material. The shame of marginality was thus not strictly a product of Paris (something distributed around Europe from a single point of origin); it was homemade, again and again, in all manner of different locations for all manner of different occasions. Why would that be?

At the level of the individual critic we can speculate, after Ander, about self-interest: feigning familiarity with distant performances might have provided a means of accumulating cultural capital. But, specialists aside, what would the average reader of the Aftonbladet (the mainstream daily from which Ander sourced his review) make of such studied disregard for local institutions? What desire did this civic masochism satisfy, or perhaps arouse? While I do not want to rush to conclusions about the intensity with which individuals or communities experienced a sense of operatic inadequacy - not least because professional critics are notoriously unreliable guides to public sentiment - Grand Opera Outside Paris does underscore the extent to which Opéra-envy has the status of historical fact; it is not something we can wish away, no matter how much we may want to decentre scholarship or provincialise Paris. At the same time, it can be hard to disentangle historical hang-ups from those of modern scholars; just like the Aftonbladet critic, we too are obliged to research widely and guard against accusations of parochialism. I suspect this goes some way to explaining why most of the authors insist that their local studies have more than local significance and why so much of this book is written in the comparative mode. Indeed, one of the takeaways from this volume is that grand opera outside Paris rarely means grand opera without Paris.

An obvious example is found in Hibberd's chapter, which charts a concerted attempt to rival Parisian magnificence by combining the forces of London's two patent theatres: Covent Garden and Drury Lane. Like many fellow contributors, Hibberd treats her readers to toe-curling comments about the vocal deficiencies on display. The reviewer for the Spectator found the Act II trio in the first London staging of Gustave III 'so badly sung ... that we should recommend its omission, not a single harmonious chord having greeted our ears from beginning to end' (56). James Robinson Planché, who had adapted Scribe's libretto for the English capital, complained that he was 'hampered with actors who couldn't sing, and compelled to cut my coat more in accordance with my cloth, than with my inclination' (56). Hibberd adopts the same tailor's lingo when she writes that Planché and colleagues 'tightened up the drama' in order to meet local expectations and that 'Gustave was consequently trimmed and simplified, in line with adaptations of other French operas at this time'. She also mentions the 'cries of "cut it short" from the gallery' that Planché attributed to London theatre audiences impatient with extended passages of singing (54). The use of the sartorial metaphor is intriguing. We know that Paris was an arbiter of fashion in more than one sense and that the notion of being $a$ la mode applied to distinct yet related domains of social and cultural life. The opera/ coat analogy feels significant. If nothing else, it provides a reminder that all adaptations are both derivative and bespoke. In Hibberd's chapter that means paying attention to the formal differences between Gustave III and Gustavas the Third: five acts became three; ensembles were largely omitted; recitative gave way to spoken dialogue; and the title role was split in two, giving audiences a speaking king and a singing lover (the latter named Lieutenant-Colonel Lillienhorn). ${ }^{13}$ The point, of course, is not simply to spot the

\footnotetext{
${ }^{13}$ Hibberd offers grateful acknowledgement of prior work on English operatic adaptation, notably Gabriella Dideriksen's 'Repertory and Rivalry: Opera at the Second Covent Garden Theatre, 1830 to 1856' (PhD diss.,
} 
difference but also to enquire as to its consequence and meaning. Hibberd's chapter is exemplary in this regard as almost every observation of a practical change serves to illuminate its dramatic significance. In the case of the aversion to ensembles, we read how 'the layering of completing voices' gave way to the 'sequential foregrounding of the protagonists'. The London staging thus emphasised 'individual motivations rather than ... the more generalised atmosphere of confusion and tension' witnessed in Paris (54).

Carolin Hauck's chapter, which follows Hibberd's in the volume and shares its concern with Gustave III, tells a more overtly political tale of operatic adaptation. Where the London version of 1833 spared the cast the trouble of singing together, the Weimar version of 1836 spared the court the spectacle of assassination. This may seem a drastic excision from a plot based on historical regicide, but accuracy in grand opera was a famously flexible concept. ('My God,' exhorted one critic cited in Ander's chapter on La juive in Stockholm in 1866, 'how these librettists deal with history!') In the specific case of Gustave III, Hauck explains that there was precedent for distancing audiences from the shocking dénouement. In Berlin in 1834 the operatic victim was not Gustave, King of Sweden, but Don Pedro, Duke of Tarazona, and the action took place not in late eighteenth-century Stockholm but sixteenth-century Palermo. The same long-gone period was chosen for a Viennese adaptation the following year, though here the setting was the Swedish seaside and now it was Duke Olaf (a fictional deputy) who stood to take the bullet on the absent king's behalf (until a last-gasp intervention, possibly demanded by the censors, saved his life and prompted the aggressor to take his own). The bloodless Weimar version, entitled Die Ballnacht, was set in seventeenth-century Transylvania and changed all of the historical names for invented ones. The title of Hauck's chapter, 'Masking the Masked Ball', is gleaned from one contemporary's comment on the ridiculousness of the dramatic contrivance:

[E]verything could pass off until Act $\mathrm{V}$ without any noticeable difference from the original. Here, right after the change of scene, the finale starts, and Elisa [Amélie] prevents the crime by throwing away her husband's pistol ... The ruler forgives his favourite and sends him and his wife to the Bulgarian Embassy. So everything ended up happily and one didn't have to worry about the future (67).

As Hauck is quick to point out, these accommodations to local sensitivities mean Die Ballnacht cannot measure up to our usual expectations of grand opera: where are the historical references (however vaguely drawn) and what about the catastrophic finale? The adaptation of Auber's score - overseen by Johann Nepomuk Hummel as director of the Weimar court orchestra - also suggests a departure from Parisian procedures. This is partly dictated by onstage events: Hauck notes the obvious omission of the music for the assassination sequence in Act V (73) and suggests that, even as early as Act II, Hummel may have been preparing the audience for a happier ending: where Auber introduces his female protagonist (Amélie) with a sudden shift from a $\mathrm{C}$ major chorus to an $\mathrm{E}$ flat minor string passage, Hummel has the equivalent character (Elisa) appear after an interlude in $\mathrm{E}$ flat major, still a striking transition from $\mathrm{C}$ major, but not one that signals ill-fortune. 'In this short instrumental passage', Hauck writes, 'we find a musical transformation that corresponds to the transformation of the text' (71). Yet that is only part of the picture.

'A deeper look at Hummel's conducting score', Hauck continues, 'shows that the majority of musical modifications were dependent on the artistic conditions and habits of the

King's College London, University of London, 1997) and Christina Fuhrmann's Foreign Opera at the London Playhouses: From Mozart to Bellini (Cambridge, 2015). 
Weimar court theatre' (71). The language here is instructive: artistic conditions and habits implies an investment in local practices and preferences. (A respect for local tailors if you will.) The fact that the Weimar court was importing performance material from Paris does not necessarily imply an asymmetry of cultural power. We learn, for instance, that Hummel cut 150 bars of 'musically redundant material' (71) from Auber's overture to Gustave III because court audiences were disinclined to sit through more than three hours of any opera. That is not a marker of aesthetic inadequacy so much as an alternative generic contract. Weimar did things differently, not worse. Needless to say, if you are seeking evidence of sub-Parisian standards, you can always find something to pique your prejudice: Hauck notes the absence of Auber's aria for King Gustave and speculates that the Weimar tenor Heinrich Theodor Knaust may not have been up to the high notes (71); the lack of a second harp or any ophicleide in the Weimar version also testifies to a relatively - and I stress, only relatively - impoverished theatre orchestra. But we also find that the local music press invoked Paris in moments of self-congratulation (as opposed to selfdeprecation). Hauck quotes a contributor to the Allgemeine musikalische Zeitung who considered Die Ballnacht 'an outstanding success'. The crowning glory was the masked ball scene, 'which really surpassed everything seen before in terms of the quantity and beauty of the masks, and which according to one traveller even far eclipsed the Parisian performance' (72). Such claims to outshine the city of light were rare, at least if we are to judge by the examples elaborated in this volume. And the anonymous traveller who complimented the Weimar staging may have been fictitious. But the point still stands that 'destination' performances were not always (or at least not only) overshadowed by towering Parisian originals. Just as often we find that destinations were in dialogue, even dispute, with other destinations.

\section{Join the dots}

Ulla-Britta Broman-Kananen's chapter merits close attention as a detailed local study of operatic practice that allows for a complex discussion of (inter)national cultural politics as well as a fresh take on two well-known works. Both Les huguenots and La muette de Portici received their Finnish premieres in Helsinki in the late 1870s - the former in a performance by the Finnish Opera, the latter in a performance at the Swedish Theatre. As the institutional names suggest, Helsinki was a multi-lingual city and grand operas were adapted accordingly. We are thus encouraged to compare not only Parisian and "peripheral' performances, but also performances that took place in the same city (Robert le diable, for instance, was performed at both houses during this period). In the case of Les huguenots, it seems the Helsinki premiere measured up reasonably well against the perceived international standard: all of the Paris ballets and chunks of Act V were cut, but the chorus and orchestra were respectably large and, judging by the praise for the Finnish soprano Emmy Achté in the role of Valentine, there was some serious vocal talent on display (116). The opera's next outing in the city came a month or so later and was bound up with a banquet to open a Finnish political assembly. Once again, we can play spot the difference with Paris (the two outer acts were now entirely excised), but that only gets us so far: on the occasion of the banquet, the three acts of Les huguenots were preceded by Aleksis Kivi's one-act play Lea. Kivi would later be celebrated as a pioneer of modern Finnish literature, and his statue now stands outside the very theatre that hosted the 1877 double-bill. As Broman-Kananen explains, the pairing of opera and play - and particularly the pairing of female protagonists - was part of a broader nationalist project. The character of Lea, though derived from the Bible, embodied 'a modest, yet brave maiden from the Finnish countryside' (117). Valentine, who was far more noble though no less humble, was thus aligned with an icon of Finnish righteousness. And, thanks to the 
omission of the Act V massacre, the evening's entertainment ended with Valentine and Raoul's Act IV love duet; instead of descending into a bloody inter-denominational showdown, the opera now redoubled the narrative optimism of Kivi's biblical play.

By considering both the divergences from Parisian practice and the affinities between Lea and Valentine, Broman-Kananen is able to paint a nuanced picture of the staging and meaning of Les huguenots at a particular place and time. ${ }^{14}$ We learn, for instance, that the omission of the massacre made it easier for the local press to present the opera's composer as a purveyor of pious goods: 'the music in Meyerbeer's most distinguished work', extolled one critic, 'is characterised by a gravity that attunes the listener's senses not only towards the pleasures of the beauty of sound, but also towards devotion, as if he had seen for himself the features of God's finger controlling the fate of mankind' (117). Indeed, it was the acting-out of genuflection that caught the attention of contemporary critics when Achté sang Valentine on three further occasions after the banquet performance. Now with the last act reinstated, audiences could enjoy the sight of a good (Protestant) woman on her knees, silent before an invisible God.

There has been much written about Valentine's status in Les huguenots: she has been described as a figure more gazed at than listened to, an ersatz 'meek self-denying maiden'. ${ }^{15}$ Broman-Kananen's argument builds on these insights to suggest the moments of muteness and meekness were put to work in the context of a very specific plan for a new, bilingual national theatre that would effectively bring the Finnish Opera under the roof of the existing Swedish Theatre. The key piece of evidence for what might seem like a suspiciously specific claim is that the plan was published and debated in tandem with the performance and reviews of the opera. For a company that lacked its own permanent venue, incorporation into such a national institution would have been something of a coup. The story, then, is not so much about Finnish attempts to keep up with French tastes - after all, Les huguenots was just shy of its fiftieth birthday by the time is reached Helsinki. Instead, Broman-Kananen suggests that the prestige accruing to successful performances of international repertoire was intended to leverage a local shift in reputations: if the Finnish Opera could pull off Les huguenots (alongside other demanding, increasingly canonical works), it would be better placed to claim cultural parity with the Swedish Theatre. To return to a running theme: what this chapter aptly demonstrates is that understanding opera on the move means doing more than holding up a peripheral copy against a Parisian (or Milanese or Viennese) original. The reality was obviously more complicated, as Broman-Kananen shows with the parallel story of La muette de Portici.

When Auber's opera premiered in Helsinki - at the Swedish Theatre in 1877 - it was received not only as an import from France (again, almost fifty years in the waiting, if anyone was counting) but also as a riposte to the contemporary offerings of the Finnish Opera. In Broman-Kananen's pithy formulation, Auber's titular character, Fenella, was a 'mute girl in a language struggle' (120). Just as Les huguenots had been paired with Kivi's Lea, La muette de Portici shared a stage with a revival of Julius Wecksell's Daniel Hjort, a historical drama, in Swedish, first performed in 1862. Wecksell may not have achieved the same level of celebrity as Kivi - in part because his career was curtailed in the mid-1860s by a diagnosis of mental illness - but his reputation is similarly

\footnotetext{
${ }^{14}$ Richard Langham Smith and Clair Rowden build a similar methodological concern into the structure of Carmen Abroad. Part I comprises half a dozen essays relating to 'The Establishment [of Carmen/Carmen] in Paris and the Repertoire' before part II invites readers 'Across Frontiers' and the essays in part III focus on 'Localising Carmen'. For Broman-Kananen the aim is to understand the 'localisation' of two other operatic heroines: Valentine and Fenella.

${ }^{15}$ Mary Ann Smart, Mimomania: Music and Gesture in Nineteenth-Century Opera (Berkeley, 2004), 115. Quoted in Ulla-Britta Broman-Kananen, 'Fenella (La muette de Portici) and Valentine (Les Huguenots) as Symbols of National Identity in Helsinki', in Grand Opera Outside Paris, ed. Jens Hesselager (Abingdon, 2017),120.
} 
bound up with long-running debates about language, literature and cultural selfdetermination. ${ }^{16}$ Once again, there was a concerted attempt to define a national and vernacular identity through opera as well as through spoken drama' (121), but with subtly different political and aesthetic priorities. In Daniel Hjort the Helsinki audience had a tale of a local peasants' revolt with obvious similarities to Masaniello's Neapolitan uprising. Broman-Kananen further draws our attention to another revival (in 1875, at the same theatre) of Kung Karls jakt, an 1852 work with music by Fredrik Pacius and a Swedish libretto by Zacharias Topelius, often cited as the first opera composed in Finland. Kung Karls jakt centres on the character of Leonora in 1672, a 'young and brave fishergirl' and 'representative of the people' who assists the Swedish King Charles at a time when Finland was still part of Sweden. As Broman-Kananen puts it, these 'more familiar dramas functioned as inter-textual frames of reference for the foreign operas' (126). In the case of La muette and Kung Karls jakt, there were numerous circumstantial similarities in terms of scenography, costume and plot (123-4), but, as with Valentine and Lea, it was the female protagonists - Fenella and Leonora - who embodied the 'national-romantic' (123) ideals of the theatre's directors and supporters.

Whether inflected by Finnish- or Swedish-leaning agendas, notions of popular sovereignty were repeatedly channelled through figures of feminine purity. That strategy will be more than familiar to students of nineteenth-century culture, but the point is that the efficacy of these figures - their ability to bring ideals to life and convey a sense of emotive, collective endeavour - was not guaranteed; in this context it depended on adapting the performing conventions of grand operas to the particular expectations of Helsinki audiences. This is where bold ideals meet brass tacks. For instance, the opening two scenes of Auber's work were removed for the performance at the Swedish Theatre. One local critic, Fredrik Berndtson, voiced the by-now-familiar presumption of inadequacy when he attributed the excision to the shortcomings of Sebastien Åberg, the (local) tenor in the part of Alphonse. It is possible that Åberg was not up to scratch, but Broman-Kananen considers an alternative logic for the apparently clumsy cut: it may, she suggests, have been an attempt to preserve the virtue of Fenella by omitting the exposition of her prior relationship with Alphonse.

In 1877, the theatre where La muette was performed endured repeated accusations of immorality, centring on (what turned out to be) a short run of Die Fledermaus. The furore surrounding Strauss's irreverent operetta was partly stoked by Helsinki's Finnish-leaning faction who seized the opportunity to protest the unedifying performances (via the traditional medium of loud whistling) and to characterise the theatre as a Swedish house of ill repute. While we learn in a footnote that Berndtson provided his readers with the missing, potentially scandalous details about Fenella and Alphonse (123 n50), what is more striking about this example of contemporary press reception is the admiration it displays for the actress Augusta Nilsson in the title role. It seems that critics on both sides of the city's language divide were partial to a strong and silent type. As with the reception of Achté's Valentine, Berndtson's highest praise is reserved for Nilsson's moments of mute expression: 'The life, the tact and grace with which Mlle N. resolves her task is really astonishing ... There is meaning and soul in every gesture.' And as with Achté's ability to embody, in the role of Valentine, a putative national spirit, Berndtson likened Nilsson's Fenella to 'an incarnated symbol of the silent sufferings of the oppressed masses' (122). Such obsessions with muteness, maidenhood and national identity were obviously not unique to Helsinki's 'opera wars', to borrow the phrase coined by the author of Kung Karls jakt (114), but it is indicative of the way that local actors (in the broad, sociological

\footnotetext{
${ }^{16}$ Whereas Kivi's statue was erected in 1939 outside the Finnish Theatre, Wecksell's was put up thirty years later outside Åbo Akademi, Finland's only (exclusively) Swedish-speaking university.
} 
sense) made their own readings of internationally circulating scripts (in the equally broad performance studies sense). Indeed, the essays in this volume repeatedly underscore both how scripted instructions could be followed with wildly varying degrees of fidelity and how actors' loyalties were sometimes divided between competing systems of aesthetic expression.

Performing grand operas outside Paris necessarily meant adapting some combination of source materials (e.g., score, libretto, dramaturgy, scenery, costumes) to suit local circumstances (the orchestra, singers and dancers at a theatre's disposal; the budget and technical expertise available for dresses and machinery; the preferred language(s) of performers and audience members; not to mention the political and confessional sensitivities of patrons, subscribers, censors et al). Somewhat paradoxically, then, the study of opera on the move requires us to understand the relatively bounded, if not fixed, potential of a given place and time. This goes some way to explaining why so many of the chapters in this volume include lengthy passages of exposition. To give examples from the chapters I have discussed: Moeckli reports on singers angling for roles by putting arias into concerts (26) and introduces us to Carl Gottlieb Hehl, an impresario active in Basel, Bern, Zurich, Besançon, Dijon, Freiburg im Breisugau, Aachen 'and sometimes several of these simultaneously', who secured Basel's Theater auf dem Blömlein its first state subsidy in the form of firewood (18). Hibberd, by contrast, summarises the lack of subsidy (combustible or otherwise) for grand opera in London (49) as well as one manager's attempts to clarify notoriously complex genre divisions (52). Ander, in turn, discusses Stockholm's local practices of role allocation and notes how music publishers in the city brought out new arrangements to coincide with upcoming performances (81).

The most elaborate example of this abundance of contextual information comes at the start of Broman-Kananen's chapter, where we quickly learn about the 'political and linguistic circumstances' that served to shape operatic performance. This is all fascinating stuff and it is clearly important for readers to know about Helsinki's three competing theatres, staging works in Finnish, Swedish and Russian, respectively. It is also important that Broman-Kananen reminds her readers - reminding, of course, is usually a euphemism for informing - that Finland was then an Autonomous Duchy of the Russian Empire within which various political factions (including the Fennoman movement) were actively petitioning the Duchy's parliament (known as the Diet of the Four Estates) for recognition of Finnish as a second official language (alongside Swedish). And this is only part of the background information: 'For this article it is crucial to know that [the Fennoman Petter] Kumpulainen [who represented the Peasants' Estate] depicted the mission of the [proposed] new [bilingual] national theatre as being educational and promoting high moral standards' (115). Broman-Kananen is right, I think, to describe this knowledge as crucial, since it helps to account for the local treatment of the two roles, which I attempted to summarise above. Nevertheless, there is a lot for the reader to take in here: as well as keeping in mind the principal theatres and their political advocates, there is the question of Finland's place within the Russian Empire, Helsinki's place within a predominantly rural society and the Just So story of the origins of the present-day Finnish National Opera (founded, as we are told in the chapter's final sentence, in 1911).

On the face of it, this might seem like the business of time-honoured, even old-fashioned opera scholarship. Indeed, you might identify this sort of contextualising imperative by any one of a number of familiar labels: thick description, reception studies or even just basic historical labour. However, I think there are subtle differences in play. Where a study of opera in Stockholm (or Setúbal or Strasbourg or wherever) tends to delimit the 
focus of enquiry, a study of opera outside Paris has the effect of encouraging at least a bilateral, if not a more complex understanding of inter-city, inter-regional and/or international relations. At the same time, a study concerned with cultural mobility tends to downgrade the importance of the individual work vis-à-vis an approach grounded in reception studies. As the chapters here demonstrate, the pursuit of a famous genre round less than musicologically famous European venues means paying attention to patterns of performance practice as much as, if not more than, discrete interpretations of works. In terms of the cumulative effect of the various case studies, I am struck by the manner in which an apparently scattered set of analyses gradually coalesce into a constellation or assemblage of discernible yet malleable relationships. The literary theorist Michael Sheringham has written along similar lines about the fields of cultural force and tension that make a place more than a set of mere co-ordinates. ${ }^{17}$ The place through which Sheringham develops his theory is the French capital and I wonder if one of the effects of the volume under review is to recast the whole of nineteenth-century Europe as a kind of 'Parisian field'. This may seem like an appalling act of post-hoc colonisation, an attempt to re-centre operatic scholarship at precisely the time when we are supposed to be broadening our horizons. Yet, as Hesselager makes clear from the off, there is no way of ignoring Paris without appearing wilfully myopic. While it is common to praise a publication for breaking new ground, in this case it seems more accurate to say that the book encourages us to revisit the ground beneath our feet and reimagine some of the fundamentals of opera history.

${ }^{17}$ Michael Sheringham, ed., Parisian Fields (Chicago, 1997).

Cite this article: Hicks J (2021). Opera History, the Travel Edition. Cambridge Opera Journal 33, 273-283. https:// doi.org/10.1017/S0954586721000094 